\section{Fatigue and general practitioners}

Nijrolder and colleagues described the diagnoses they found during follow-up of patients presenting with fatigue in primary care. ${ }^{1}$ Our study (prospective, cross-sectional, within a one-year period $^{2}$ ) was performed to determine accompanying reasons for the encounter, symptoms, diagnostic procedures, recent diagnoses and therapeutic procedures in patients suffering from fatigue in a primary care setting. Fatigue was associated with acute infectious diseases of the respiratory tract, anemia, mental disorders, heart and circulation problems and nephropathies. The low rate of diagnoses at the initial consultation stated by Nijrolder and colleagues may be due to a watchful waiting strategy. Our investigation revealed that about $70 \%$ of the patients with fatigue were asked to see their general practitioner again. Watchful waiting seems to be a proper strategy after excluding cardiovascular problems and severe infections. This is supported by earlier investigations of Kenter and colleagues, ${ }^{3}$ who found that fatigue is often a temporary story.

\section{Thomas Frese MD \\ Kristin Herrmann MSc \\ Hagen Sandholzer MD \\ Department of Primary Care, Leipzig \\ Medical School, Leipzig, Germany}

\section{REFERENCES}

1. Nijrolder I, van der Windt D, de Vries H, et al. Diagnoses during follow-up of patients presenting with fatigue in primary care. CMAJ 2009; DOI:10. 1503/cmaj.090647.

2. Wockenfuss R, Frese T, Herrmann K, et al. Threeand four-digit ICD-10 is not a reliable classification system in primary care. Scand J Prim Health Care 2009;27:131-6.

3. Kenter EG, Okkes IM, Oskam SK, et al. Tiredness in Dutch family practice. Data on patients complaining of and/or diagnosed with "tiredness." Fam Pract 2003;20:434-40.

For the full letter, go to: www.cmaj.ca/cgi/eletters /cmaj.090647v1\#232962

DOI:10.1503/cmaj.109-2050

\section{The big picture of medical transport}

The report by Singh and colleagues ${ }^{1}$ adds significantly to the broader discus- sion of regionalized health care and the risks of transporting patients to distant areas for care. In addition to the risks associated with the actual transportation of the patient, studies also need to address the issues faced by patients prior to "lifting off from home" and what happens at the "other end." Health care professionals seeking more advanced care for their patients often have to search for significant lengths of time before a receiving centre and team can be found. Once a receiving centre is identified, there are often further delays for a multitude of reasons ranging from the weather to the expertise of the transporting team. Such delays can make a difference to patients with serious problems. Understanding the fuller extent of these "transport issues" and the effects and costs that they have is really required.

Michael D. Cusimano MD MHPE

St. Michael's Hospital, Division of Neurosurgery, University of Toronto, Toronto, Ont.

\section{REFERENCES}

1. Singh JM, MacDonald RD, Bronskill SE, et al. Incidence and predictors of critical events during urgent air-medical transport. CMAJ 2009;181:579-84.

For the full letter, go to: www.cmaj.ca/cgi/eletters /181/9/579\#232134

DOI:10.1503/cmaj.109-2051

\section{Asthma in older adults}

Asthma is frequently overlooked in the geriatric population, as in the present review by Meyer S. Balter and colleagues. ${ }^{1}$ Asthma in older adults is associated with a significant number of hospitalizations and emergency department visits, which lead to substantial amounts of health care costs. Even when discovered, it is often undertreated. ${ }^{2}$ The hallmark symptoms of asthma, including episodic shortness of breath, wheeze and cough, are nonspecific in older adults and are mimicked by other diseases, such as congestive heart failure, emphysema and chronic bronchitis, chronic aspiration, gastroesophageal reflux disease and tracheobronchial tumours. Several things must be taken into account when considering appropriate pharmacologic therapy in older patients, including poor inhaler technique, differences in pharmacodynamics and pharmacokinetics than in the younger population, diminished response to $\beta_{2}$-agonists, comorbidities, complex regimen, prohibitive cost and poor memory.

\section{Akashdeep Singh \\ Adesh Institute of Medical Sciences \& \\ Research, Bathinda, India}

\section{REFERENCES}

1. Balter MS, Bell AD, Kaplan AG, et al. Management of asthma in adults. CMAJ 2009; DOI:10. 1503/cmaj.080007.

2. Mannino DM, Homa DM, Akinbami LJ, et al. Surveillance for asthma: United States, 1980-1999. MMWR Surveill Summ 2002;51:1-13.

For the full letter, go to: www.cmaj.ca/cgi/eletters /cmaj.080007v1\#229616

DOI:10.1503/cmaj.109-2049

\section{Correction}

The "Letter from the Editor: No longer free for all", , published Nov. 24, said that access to reviews, analysis, practice, commentaries, humanities and supplements will be restricted to CMA members as of January 2010. In fact, that content will also be available to subscribers and pay-per-view readers.

\section{REFERENCE}

1. Hébert PC. Letter from the Editor: No longer free for all. CMAJ 2009;DOI:10.1503/cmaj.091910

DOI:10.1503/cmaj.109-2053

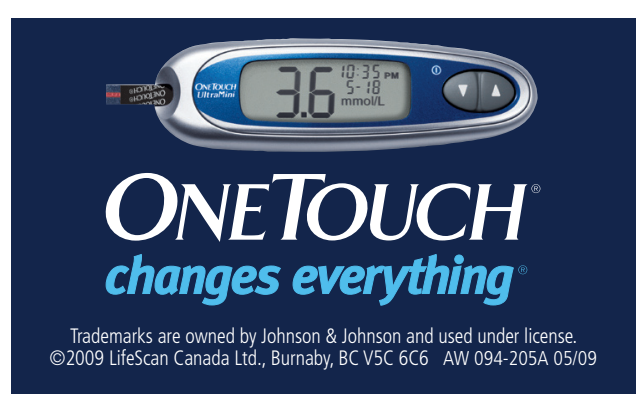

